\title{
Growth and scale improvement of Israeli carp (Cyprinus carpio) based on genetic breeding
}

Jung Eun Kim

NIFS

Ju-ae Hwang

NIFS

Hyeong Su Kim

NIFS

Jae Hyun Im

NIFS

Jeong Ho Lee ( $\square$ jhlee7124@korea.kr)

NIFS https://orcid.org/0000-0002-2236-3748

Research article

Keywords: Israeli carp, Cyprinus carpio, genetic breeding, parentage analysis

Posted Date: February 28th, 2020

DOI: https://doi.org/10.21203/rs.3.rs-15419/v1

License: (c) (1) This work is licensed under a Creative Commons Attribution 4.0 International License.

Read Full License 


\section{Abstract}

Background: There is a need to recover the genetic diversity of Israeli carp by continuous inbreeding and develop genetics-based breeding for rapid growth, better body shape, and improved scales. However, there are no breeding studies on developing domestic Israeli carp since 1973. To develop an Israeli carp breed that grows fast and has improved body shape and scale using genetic breeding methods.

Results: Four breeding groups were set. A mating scheme was developed considering the morphological analysis and genetic distance of broodstock. F1 was produced according to the mating scheme. The Korea $\times$ China group grew faster in 17 months. Total length in the China $\times$ Korea group was small, but body height was similar to that of the other groups, and the condition factor was the highest. Common Israeli carp in Korea reached $1.7 \mathrm{~kg}$ in 17 months, and improved Israeli carp reached to $2.2 \mathrm{~kg}$. The scale scores of the F1 group were 1.98 (China $\times$ China), 2.68 (China $\times$ Korea), 2.36 (Korea $\times$ China) and 3.18 (Korea $\times$ Korea). The average number of scales crossing between China and Korea was 2.52 and broodstock group was 3.15. F1 showed lower scale score (0.63) than broodstock.

Conclusions: The improved carp has better scales than parent group, which improved in weight and scales compared to common Israeli carp. The Israeli carp developed by the genetics-based breeding grew quicker and had improved fewer scales, which will be of great value for domestic Israeli aquaculture industry due to good marketability.

\section{Background}

Common carp is one of the species that make up the aquaculture industry in different countries in Europe and Asia. Common carp breeding has been studied in many countries worldwide. The improved carp developed by breeding is then exported to other countries [1]. In particular, carp breeding studies brought early prosperity in Europe [2-4]. The best breed of the Israeli carp had been established in the 1970s, called "Dor 70 strain" or "Israeli mirror carp". During this time, South Korea and China imported carp from Israel $[5,6]$. The Israeli carp strain is currently the most widely distributed fish in the world and is being cultured in many parts of Europe and Asia $[7,8]$.

Since the introduction of Israeli carp into Korea for farming in 1973, inland fish-aquaculture flourished dramatically because Israeli carp became the new popular dish among Korean people. Wide use of net cage in reservoirs made mass production of freshwater fish possible [9-11]. However, the popularity of this fish for human consumption also dropped dramatically since 1998 when the carp stocks were affected by a variety of diseases and parasites. More than $70 \%$ of carp farms in many regions of the country have suffered heavy economic losses due to disease outbreaks [12], and some Israeli carp aquafarms were forced to close in Korea. Mass mortality during the events was caused by the low immunity of the highly inbred fish stocks. The same problem is known to have occurred among carps in Bangladesh $[13,14]$. In addition, loss of genetic diversity using the wrong mating scheme is blamed for the mass mortality. Simple general mass mating was carried out in the fish farms in Korea without any 
designed approaches or a mating scheme for selective breeding. This approach is believed to have caused a rapid decline of genetic diversity as only some groups of fish were repeatedly involved in mating. It is urgent to study breeding improvements considering the genetic distance of Israeli carp in Korea [11].

Improving a fish breed is an important global issue, and many previous reports related to a variety of fish including Atlantic salmon, tilapia, common carp and rainbow trout are available. For example, Norway had notable success in government-operated research on Atlantic salmon breeding in 1968 [15]. Norway captured $90 \%$ of the global salmon market (1,231 tons), and its tilapia market grew by $20 \%$ each generation. China has developed and commercialized a superior breed of common carp by integrating traditional method for breeding with molecular breeding technique [16]. German mirror carp (Cyprinus carpio) is a popular freshwater fish reared in Europe because of its fast growth rate, feeding efficiency, cold resistance, and ease in domestication. The German mirror carp was introduced to China in 1984 but could not adapt well to foreign aquaculture conditions [17]. Therefore, the Heilongjiang River Fishery Institute conducted a breeding study for obtaining an improved variety [17]. After several years, a selected strain called the "Songpu mirror carp" was successfully bred. It has the positive characteristics of the German mirror carp, such as few scales and high growth, high survival rate, and improved disease resistance [17].

Korean fishermen prefer the type of Israeli carp, which have fewer scales. Because it is easy to trim, it is on high demand. In addition, the size and shape of the Israeli carp in Korea are currently undesirable, in Korea; however, no breeding studies have been conducted since the introduction of Israeli carp in the 1970s to develop a superior breed in Korea [11]. Since the products of inland-water fish farming is an important part of national food security, developing an improved fish breed with a strong potential for commercially competitive value is crucial in sustaining national economy [18]. In order to improve the breeding of domestic Israeli carp, a previous study was conducted to improve the size and scale by crossing with Chinese species [19].

The purpose of this study was to develop an Israeli carp breed that grows fast and has improved body shape and scale by using genetic breeding methods. We compared earlier growth up to 170 days of age in a previous study. However, we did not compare the growth at 17 months of age at the time of shipment. In addition, Israeli carp scales increase with growth, so it is difficult to determine the scale factor until after 170 days accurately. Therefore, we conducted a study on the growth and scale of the developed Israeli carp first generation (F1) at the time of shipment and compared it with the parent.

\section{Results}

\section{Broodstock selection and F1 production}

We analyzed gene distance and morphological characteristics of fish for genetic breeding. In a previous study, we had analyzed the genetic diversity and distance between Chinese broodstock and Korean broodstock relatives [23]. Genetic analysis showed that the genetic distance between the Korean and the 
Chinese carps ranged from 0.432 to 0.594 on average, and the genetic distance was at least 0.2 or more. The scale scores were 3.71 (KorA), 3.89 (KorB), 2.38 (ChA) and 2.61 (ChB). In the case of Korean Israeli carp, the scale score was mainly 4 , while the scores of Chinese Israeli carps were mainly 1 . The average scale index of the Korean carps was 3.8, and the average scale index of the Chinese carps was 2.5, indicating that the Chinese carps had less scales than the Korean carps (Fig. 1). In addition, top 40\% broodstock was selected via morphological analysis. As a result, 100 out of $254 \mathrm{~F} 0$ broodstock were selected (Table 2). The F1 was produced according to the mating scheme. Specifically, they were selected as 11 Korean females, 14 Korean males, 19 Chinese females, 56 Chinese males. A total of four mating groups were set up and then produced $\mathrm{F} 1$ in each tank as described in the materials and methods section. Egg production per group was $400 \mathrm{~mL}$ for CC, 8,000 mL for CK, 3,000 mL for KC and KK, 1,000 $\mathrm{mL}$ for common Israeli carp. Hatching was achieved in an artificial incubator (Table 3).

\section{Parentage test and family analysis}

In order to determine the objective breeding efficiency and to utilize the tank efficiently, 30-day-old fish after hatching were collected for each group, and were mixed and kept in a single tank for up to 17 months in the same breeding conditions. Fins were collected for genotype analysis of 1,500 surviving (17month-old) fish. Multiplex PCR was performed using a microsatellite marker, and genetic diversity and parentage analysis were performed using amplified products. Parentage analysis of total 1,398 (F1) individuals showed $93 \%(1,398 / 1,500)$ success rate. The parentage analysis was conducted to identify the cross groups of individuals.

As a result of parentage analysis, KC (441) was the highest, followed by KK (408), CK (235) and CC (136). The number of families was the highest in KC (60), followed by CC (59), CK (37), KK (36). Common Israeli carp identified 138 individuals and 28 families.

\section{Morphological comparison of F1}

For seed production, the broodstock F0 was selected for high length and weight first, and then fewer scales. Mating methods for seed production divided broodstock into four mating groups.

In a previous study, we had analyzed the initial growth of each group. On the 170th day, the size of the $\mathrm{CC}, \mathrm{CK}$, and KC groups was measured at $90.32 \pm 22.64 \mathrm{~mm}, 90.80 \pm 16.90 \mathrm{~mm}$, and $88.31 \pm 19.00 \mathrm{~mm}$, respectively [19]. The size of KK group was measured as $76.77 \pm 14.58 \mathrm{~mm}$. The measured size on the 170th day was larger in the $\mathrm{CC}, \mathrm{CK}$, and $\mathrm{KC}$ groups than that in the KK group.

In this study, we compared and analyzed the morphology characteristics at 17 months. At 17 months of age, the total length and weight of four groups were as follows: CC (483.60 $\pm 25.29 \mathrm{~mm}, 2260.00 \pm$ $260.00 \mathrm{~g}), \mathrm{CK}(471.52 \pm 23.31 \mathrm{~mm}, 2160.00 \pm 240 \mathrm{~g}), \mathrm{KC}(491.77 \pm 26.14 \mathrm{~mm}, 2270.00 \pm 260 \mathrm{~g})$ and KK $(475.72 \pm 23.11 \mathrm{~mm}, 2190.00 \pm 250.00 \mathrm{~g})$ (Fig. 2). Total length and weight were the highest in KC, followed by CC, KK, and CK groups. However, the total length of CK group was the lowest, but body height was similar to that of the other groups. CK was characterized by high body height. CK showed the 
shortest body length, but its CF value was the highest. Analysis of F1 breeding groups revealed that CC and CK rapidly grew in terms of overall length and body weight since early stages of the life cycle. The participation of Chinese parents was considered to have a positive impact on initial growth. The late growth (17 months) was significantly higher in $\mathrm{KC}$, and it was also found that the height of Korean Israeli carps was high. High growth rate and body shape improvement were observed in Chinese and Korean hybrids. The results excellently exemplified the positive effect of the crossbreeding (Table 4). Besides, the difference in total length between the $\mathrm{CK}, \mathrm{KC}$, and the common Israeli carp was $39.80 \mathrm{~mm}$ and the weight was $475 \mathrm{~g}$. The common Israeli carp reached $1.7 \mathrm{~kg}$ in 17 months, and improved Israeli carp reached 2.2 $\mathrm{kg}$.

\section{Distribution of scales in the F1 generation}

In order to estimate the incidence of scales, the scoring system was set from 1 to 5 according to the degree of a body scale. Scale index measured for each group was based on the score. In the analysis of scale scores of F1 carps, the average scale score was 2.55. The scale scores of the CC group were $1.98 \pm$ 1.15 , while it was $2.68 \pm 1.05$ in the CK group, $2.36 \pm 1.34$ in the KC group and $3.18 \pm 0.82$ in the KK group (Fig. 2). The scale score was the lowest in CC group, followed by KC, CK and KC. The scale score of the $\mathrm{F} 1$ breeding groups $(\mathrm{CK}, \mathrm{KC})$ was 2.52 , indicating that $\mathrm{F} 1$ breeding groups had fewer scales than broodstock (3.15) (Fig. 3). In particular, it was confirmed that scale distribution was much improved relative to the average of common Israeli carp in Korea (3.36). The scale distribution was less in the mating group, in which more Chinese-born mothers participated than the KK group, and the scale trait of Israeli carp could be effectively managed by cross-breeding.

\section{Discussion}

In this study, we aimed to improve the Israeli carp into a fast growing one with fewer scales. We conducted crossbreeding between the domestic Israeli and Songpu carps introduced in China. As a result, total length and weight were the highest in $\mathrm{KC}(491.77 \mathrm{~mm}, 2270.00 \mathrm{~g})$, followed by CC $(483.60 \mathrm{~mm}$, $2260.00 \mathrm{~g}), \mathrm{KK}(475.72 \mathrm{~mm}, 2190.00 \mathrm{~g})$, and CK (471.52 mm, $2160.00 \mathrm{~g})$ groups. The KC group grew faster in 17 months. However, total length of the CK group was small, but body height was similar to that of the other groups and the condition factor was the highest. Scale scores of the F1 group were, 2.08, $2.49,2.28$, and 3.26 for the $\mathrm{CC}, \mathrm{CK}, \mathrm{KC}$, and $\mathrm{KK}$ groups, respectively. The average number of scales crossing between Chinese and Korean (F1, CK, and KC) was 2.39 and broodstock group (F0) was 3.15. F1 showed 0.76 lower scales than the broodstock, indicating that F1 improved the scales.

Seeds were produced from four group matings. Crossbreeding experiments have showed that different combinations of parents show positive heterosis, which manifests as increased growth rates, survival, and feeding conversion [24]. The initial water temperature was maintained at $23^{\circ} \mathrm{C}-25^{\circ} \mathrm{C}$ for the best culture conditions in this study.

Initial growth had been carried out in the previous study, and the morphological analysis of the 17-month selling period was performed in this study [19]. In a previous study, at days 60 and 170 of culture, the 
length and weight of the $\mathrm{CC}, \mathrm{CK}$, and $\mathrm{KC}$ group were significantly higher than those in the KK group $(\mathrm{P}<$ 0.05). The $\mathrm{CF}$ was also high in the $\mathrm{CC}$ and $\mathrm{CK}$ group [19]. Our results of length and weight measurement were higher in the Chinese broodstock group than those in the Korean broodstock group. Generally, the growth rates of fish are influenced by many internal and external factors, though the female broodstock appeared to be more intensely affected $[25,26]$. As a result, the initial growth of the CC and CK groups seemed to be similar to that of the Chinese parents due to the influence of Chinese females. Contrarily, the KC group grew faster after 17 months. After 17 months, total length in the CK group was small, but body height was similar to that in other groups and CF was the highest (Fig. 2). This should have a significant effect on the improvement of the merchandise due to the increase in the edible portion. The latter half of growth is largely influenced by environmental factors. KC showed high environmental adaptation. As a result of a comparison of the scale scores of the broodstocks F0 and F1, broodstock F0 was found to have an average of 3.15, while F1 breeding groups (CK, KC) had an average scale score of 2.52. F1 had a better scale condition than the broodstock F0. Through this study, growth, condition factor (body shape), and scales were improved (Fig. 3).

It is essential to consider whether improved breeding traits can cause physiological problems in fish. The Songpu mirror Carp has fast growth, an improved body shape, and few scales than the comparatively scaly German carp [17]. According to the study of Hwang et al. (2015) on the Israeli carp in Korea, the survival rate was up to 170 days in each group (CC, CK, KC, KK), and the survival rate was $100 \%$ in all groups [19]. In addition, Israeli carp have demonstrated resistance to parasites through releasing mucus in their saliva. This physiological activity appears to have been an adaption due to reduction of scales. It can be generally stated that growth, CF (Condition Factor), body shape, and scale improvement do not cause physiological problems in individual fish. However, for a more precise study, it is necessary to present objective data through artificial infection trials.

\section{Conclusions}

The Israeli carp (F1) developed by the genetic analysis-based breeding method grew quicker and had improved body shape and fewer scales. The improved Israeli carp (F1; CK, KC) in this study grows faster than the common Israeli carp so that it is possible to save both cost and time. The common carp from a general culture farm had been cultivated for two years (24 months) and were sold when the weight was $1.5 \mathrm{~kg}$ [27]. The common Israeli carp in Korea reached $1.7 \mathrm{~kg}$ in 17 months, and improved Israeli carp reached $2.2 \mathrm{~kg}$. The improved carp (F1; CK, KC) had $20 \%$ better scales than the parent group (F0), which improved $27 \%$ in weight and $25 \%$ in scales compared to common Israeli carp. Hence, the improved carp is more economical than the common Israeli carp. Further, since its body shape was improved, the edible portion also improved. Moreover, since it has fewer scales, the commerciality of the improved carp is

expected to increase and should be highly acceptable by the aquaculture industry in Korea. In this study, we did not focus on the expression of specific genes on growth and scales of each group. In future studies, the study on the expression difference of useful genes in each group should be conducted. 


\section{Methods}

\section{Sample collection}

Israeli carp (C. carpio) fishes were collected from Chungnam (KorA, 47 samples, 2-3-year-old) and Jeonbuk (KorB, 51 samples, 2-3-year-old) in Korea, and samples of cultured Chinese Israeli carp ( $C$. carpio) were collected from Jilin province (ChA, 76 samples, 2-3-year-old) and Heilongjiang province (ChB, 80 samples, 2-3-year-old) in China (Table 1).

\section{Basic morphological analysis}

A total of 98 of Korean Israeli carps and a total of 156 Chinese Israeli carps were measured using a ruler and Vernier calipers for total length, body length, weight and body height. Condition factor (CF) and body shape were calculated using the following formula: CF; Body weight $(\mathrm{g}) /$ Total length $(\mathrm{mm})^{3} \times$. Fish were classified into 5 classes based on a 5-step scoring system of scale distribution: 1 score (0 3 scales), 2 score (4 10 scales at some dorsal fin scales), 3 score (14 17 scales at dorsal fin and tail), 4 score (18 33 scales at dorsal fin, tail and sideline) and 5 score ( $\geq 34$ scales at dorsal fin, tail and sideline and whole abdomen). RFID (Radio Frequency Identification) tags were inserted into all individuals of the broodstock, and the morphometric analysis each individual was managed by measuring the total length, body length, weight, CF, body shape and scale value according to each unique number. The collected broodstocks were anesthetized for genetic analysis and morphological measurement. The groups were anesthetized by immersion in $100 \mathrm{mg} / \mathrm{L}$ MS-222 (Sigma, MO, USA) diluted in water. After the fin $\left(1 \mathrm{~cm}^{2}\right)$ was taken and stored in ethanol tube (99.9\%). RFID tags were inserted into all individuals of the broodstock. Immediately after the measurement, they recovered from anesthesia in the recovery tank. And then, they were sent to the rearing tank for management.

\section{Broodstock selection and mating scheme}

The breeding experiments of cultivated Israeli carp were carried out using the broodstock F0 carps, which consists of the Korean and the Chinese Israeli carps. In the spring, sexually mature breeders were selected for production of families. Selection of broodstock is based on genetic analysis and morphological analysis. Based on genetic analysis of a total of 254 broodstock, male individuals with a calculated value of the genetic relationship with females and a genetic distance value of 0.2 or less were excluded. Overall, 100 broodstock samples were selected based on morphological characteristics. Specifically, the total weight, $\mathrm{CF}$, and scale score were converted into 10 points, and the breeding value was calculated by the total weight $(70 \%), \mathrm{CF}(20 \%)$, and scale score $(10 \%$, scale score 2 or less) for each item, i.e., breeding

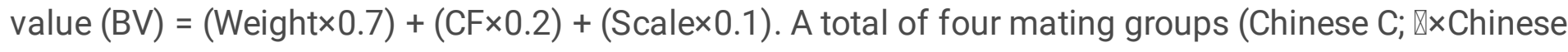

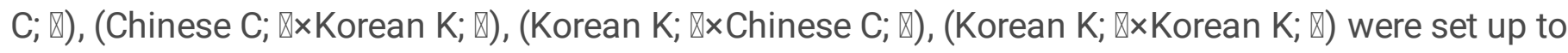
produce F1. We selected a Korean Israeli carp with mean measurement traits and set up a mating scheme to compare with common Israeli carp in Korea. According to the mating scheme, female and male were placed in each tank and spawned through water temperature stimulation (maintenance at $25^{\circ} \mathrm{C}$ ). When 
egg spawning completed, eggs were collected and hatched using an artificial incubator. After 30 days of age, individuals from each group were randomly selected and raised in one tank.

\section{Morphological analysis of F1 group}

The produced F1 was analyzed from 20 to 170 days after hatching and once more at 17 months. Fish were randomly sampled from the tank, and used for growth and scale measurements and genotype analysis. The F1 group were anesthetized by immersion in 100mg/L MS-222 (Sigma, MO, USA) diluted in water. After the fin $\left(1 \mathrm{~cm}^{2}\right)$ was taken and stored in ethanol tube $(99.9 \%)$. Immediately after the measurement, they recovered from anesthesia in the recovery tank. And then, they were sent to the rearing tank for management. Length and individual mean weight were measured using the ZEN lite 2012 software program. Then, an RFID tag was inserted into each carp of the selected F1 generation offspring, and the metric trait data for each individual were collected by measuring the total length, height, weight, $\mathrm{CF}$, and scale score for each unique RFID number.

\section{DNA extraction, PCR and parentage analysis}

Fin samples of F1 (1,500 samples) and broodstock F0 (100 samples) were collected and preserved in $99.9 \%$ ethanol and transferred to the laboratory for DNA extraction [20]. Each sample was mixed with 5\% Chelex 100 (Bio-Rad Laboratories, Hercules, USA) and 1\% proteinase K (Roche, USA) in sterile water, incubated at $55^{\circ} \mathrm{C}$ for 1 hour and then incubated at $100^{\circ} \mathrm{C}$ for $10 \mathrm{~min}$. The mixture was centrifuged, and the supernatant was retained. Six suitable markers were selected to distinguish diversity in carp. For PCR, we used primer pairs designed to amplify markers MFW1, MFW14, MFW16, MFW24, MFW26, and MFW30 [21] and subjected the forward primers to fluorescent dye labeling. The following primers were used: MFW01, forward 5'-GTCCAGACTGTCATCAGGAG-3' and reverse 5'-GAGGTGTACACTGAGTCACGC-3'; MFW14, forward 5'-CAGAAGCTTCTGGAAATCTGAG-3'and reverse 5'-GCGAGAAGATTGATGGACAAC-3'; MFW16, forward 5'-GTCCATTGTGTCAAGATAGAG-3'and reverse 5'-TCTTCATTTCAGGCTGCAAAG3';MFW24, forward 5'-GCTCCAGATTGCACATTATAG-3'and reverse 5'-CTACACACACGCAGAGCCTTTC3';MFW26, forward 5'-CCCTGAGATAGAAACCACTG-3'and reverse 5'-CACCATGCTTGGATGCAAAAG3';MFW30, forward 5'-GGTCAACAAGTAGTTGTGCAG-3'and reverse 5'-CCATCTCTGTCATTGCAACAG-3'. Each $20 \mu \mathrm{L}$ reaction mixture contained 2-4 $\mu \mathrm{L}$ template DNA (100 150 ng), forward and reverse primers each $0.5 \mathrm{mM}$, 1x F-star Taq Reaction buffer (BioFact, Korea), $0.2 \mathrm{mM}$ of dNTP (BioFact, Korea), $1.25 \mathrm{U}$ of F-star Taq DNA polymerase (BioFact, Korea), and $1 \mu \mathrm{L}$ dimethyl sulfoxide (Sigma St Louis, USA). Thermal cycling was conducted on an Applied Biosystems thermal cycler (\#9902) using the conditions as follows: $95^{\circ} \mathrm{C}$ for 2 min followed by 30 cycles of $95^{\circ} \mathrm{C}$ for $30 \mathrm{~s}, 58^{\circ} \mathrm{C}$ for $30 \mathrm{~s}$, and $72^{\circ} \mathrm{C}$ for $30 \mathrm{~s}$, followed by a final extension at $72^{\circ} \mathrm{C}$ for $10 \mathrm{~min}$. The generated products were confirmed by $2 \%$ agarose gel electrophoresis. For fragment analysis, $1 \mu \mathrm{L}$ of each PCR product was combined with formamide and a 500 LIZ size standard (GeneScan ${ }^{\text {TM }} 500$ LIZ; Applied Biosystems, USA), and the mixture was subjected to capillary electrophoresis on an ABI 3130 DNA Sequencer (Applied Biosystems, USA). The results were analyzed using the GeneMapper version 4.0 fragment analysis software (Applied Biosystems, USA). The parentage test was performed using the PAPA 2.0 program using genotyping data. 


\section{Statistical analysis}

Results were expressed as mean \pm SD, and SPSS program was used for statistical significance test of all mean values for each measurement value. Significance was tested by t-test and ANOVA. The significance criterion for all $P$ values was 0.05 . The data were analyzed by one-way ANOVA using the SPSS statistical package (SPSS 5.0; SPSS Inc., USA). Means were separated using Duncan's multiple range test and were considered significantly different at $P<0.05$ [22].

\section{Abbreviations}

ANOVA:One-way analysis of variance; $\mathrm{BL}$ :body length; $\mathrm{BH}$ :body height; Body shape:height/length ratio; CF:condition factor; PCR:Polymerase chain reaction; RFID tag:Radio Frequency Identification tag; TL:total length; TW:total weight

\section{Declarations}

\section{Acknowledgements}

We would like to express our sincere thanks to both Chinese Academy of Fishery Sciences, Heilongjiang River Fisheries Institute and Dr. Lianyu SHI for your active participation and cooperation on proceeding this research.

\section{Authors' contributions}

JEK and JHL designed the experiments, JEK and JAH performed experiments, JEK, JAH, HSK, JHI and $\mathrm{JHL}$ attended the data analyses and discussion. JEK: Wrote the manuscript, JAH, HSK, JHI and JHL revised the manuscript. All authors read and approved the final manuscript.

\section{Funding}

This work was supported by a grant from the National Institute of Fisheries Science (R2020002), Korea. Funds were used for the design of the study and collection, analysis and interpretation of data and in writing the manuscript, as well as in the open access payment.

\section{Availability of data and materials}

The datasets used and/or analyzed during the current study are available from the corresponding author on request

\section{Ethics approval and consent to participate}

Chinese Israeli carp was imported from Chinese Academy of Fishery Sciences, Heilongjiang River Fisheries Institute for research purposes. This study was carried out under the permission (2017-NIFSIACUC-13) from the National Institute of Fisheries Science, NIFS, South Korea. We declare that all of the 
experiments described herein comply with the current laws of Korea (Ordinance of Agriculture, Food and Fisheries, No. 1, Regarding Experimental Animals, no. 9932).

\section{Consent for publication}

Not applicable.

\section{Competing interests}

The authors declare that they have no conflict of interest.

\section{Author details}

${ }^{1}$ Inland Aquaculture Research Center, National Institute of Fisheries Science (NIFS), Changwon 51688, Korea

${ }^{2}$ Research Cooperation Division, National Institute of Fisheries Science (NIFS), Busan 46083, South Korea.

\section{References}

1. Moav $\mathrm{R}$ and Wohlfarth $\mathrm{Ci}$ Two-way selection for growth rate in the common carp (Cyprinus carpio L.). Genetics. 1976; 82: 83-101.

2. Tal S and Sheluvki M. A review of the fish farming industry in Israel. Trans Am Fish Soc. 1952; 81: 218-223.

3. Yashouv A. The Punten carp and its attributes. Bamidgeh. 1955; 7: 46-55.

4. Hulak M, Kaspar V, Kohlmann K, Coward K, Tešitel J, Rodina M, Gela D, Martin K, Linhart O. Microsatellite-based genetic diversity and differentiation of foreign common carp (Cyprinus carpio) strains farmed in the Czech Republic. Aquaculture. 2010; 298: 194-201.

5. Wohlfarth Ci, Lahman M, Hulata G and Moav R. The story of Dor-70: a selected strain of the Israeli common carp. Bamidgeh. 1980; 32: 3-5.

6. Sin AW. Stock improvement of the common carp in Hong Kong through hybridization with the introduced Israeli race Dor-70. Aquaculture. 1982; 29: 299-304.

7. Wohlfarth GW, Moav R and Hulata G. A genotype-interaction for growth rate in the common carp, growing in intensively manured ponds. Aquaculture. 1983; 33: 187-195

8. Li D, Kang D, Yin Q, Sun X, Liang L. Microsatellite DNA Marker Analysis of Genetic Diversity in Wild Common Carp (Cyprinus carpio L.) Populations. J Genet Genom. 2007;34: 984-993.

9. Lee SY. Expenses of water quality preservation measures of Deacheong dam. 1992;78: 17-20.

10. Kim JG. The Study of Identifying Ecological Characteristics and Farming Conditions for the Restoration of Mandarin Fish Stocks. (Master's thesiss) Gyeongnam National University of Science and Technology. 2016 
11. Kim JE. Genetic Breeding of Israeli Carp (Cyprinus carpio) using Microsatellite Markers. (Doctoral thesiss) Kyungsung University. 2018

12. Oh MJ, Jung SJ, Choi TJ, Kim HR, Rajendran KV, Kim YJ, Park MA, Chun SK. A viral disease occurring in cultured carp Cyprinus carpio in Korea. Fish Pathol 2001; 36:147-151.

13. Rajts F, Huntington T, Hussain MG. Carp broodstock management and genetic improvement program under Fourth Fisheries Project. In: Penman DJ, HussainMG, McAndrew BJ, Mazid MA (eds) Genetic management and improvement of exotic carp species in Bangladesh. Bangladesh Fisheries Research Institute Mymensingh. 2002; 95-106.

14. Mondol MRK, Islamz MS, Alam MS. Characterization of different strains of common carp (Cyprinus carpio L.) (Cyprinidae, Cypriniformes) in Bangladesh using microsatellite DNA markers. Genet Mol Biol. 2006; 29: 626-633.

15. Trygve G. Genetic improvement for the development of efficient global aquaculture: A personal opinion review. Aquaculture. 2012; 344-349

16. Dong Z, Nguyen H, Zhu W. Genetic evaluation of a selective breeding program for common carp Cyprinus carpio conducted from 2004 to 2014. BMC Genetics. 2015; 16: 1-9.

17. Li CZ, Y JZ, Hu X, Shi L. Comparative studies on measurable characters and the number of scales in Songpu mirror carp and German mirror carp selection strain. Chi J Fish. 2009; 22: 53-61.

18. Korea Fisheries News. Trout, producers need comarketing (2015-4-20) Korean trout farming association. 2015a

19. Hwang JA, Goo IB, Kim JE, Kim MH, Kim DH, Im JH, Choi HS and Lee JH. Growth Comparison of Israeli Carp (Cyprinus carpio) to Different Breeding Combination. Developmant \& Reproduction. 2016; 20(4); 275-281.

20. Yue GH, Orban L. Rapid Isolation of DNA from fresh and preserved fish scales for polymerase chain reaction. Mar Biotechnol. 2001; 3: 199-204.

21. Crooijmans RPMA, Bierbooms VAF, Komen J, VanderPoel JJ, Groenen MAM Microsatellite markers in common carp (Cyprinus carpio L). Anim Genet. 1997; 28: 129-134.

22. Duncan DB. Multiple-range and multiple $F$ tests. Biometrics. 1955; 1:1-42.

23. Kim JE, Goo IB, Hwang JA, Kim HS, Choi HS, Lee JH. Genetic variability comparison of cultured Israeli carp (Cyprinus carpio) from Korea using microsatellites. Genes \& Genomics. 2018; 40: 653642.

24. Bakos J. Genetic improvement of common carp strains using intraspecific hybridization. Aquaculture. 1995; 129: 183-186.

25. Heath DD, Fox CW, Heath JW. Maternal effects on offspring size: Variation through early development of Chinook salmon. Evolution. 1999; 53: 1605-1611.

26. Marc V, Martin K, Stephane M, Mathilde DN, Daphne DG, Marek R, David G, Dominique V, Bernard C, Otomar L. Heritability estimates for growth-related traits using microsatellite parentage assignment in juvenile common carp (Cyprinus carpio L.). Aquaculture. 2004; 235: 223-236. 
27. Martin K, Stéphane M, Marek R, David G, Otomar L, Marc V. Heritability estimates for processing and quality traits in common carp (Cyprinus carpio L.) using a molecular pedigree. Aquaculture. 2007; 270: 43-50.

\section{Tables}

Due to technical limitations, all table files are only available for download from the Supplementary Files section.

Figures 
A
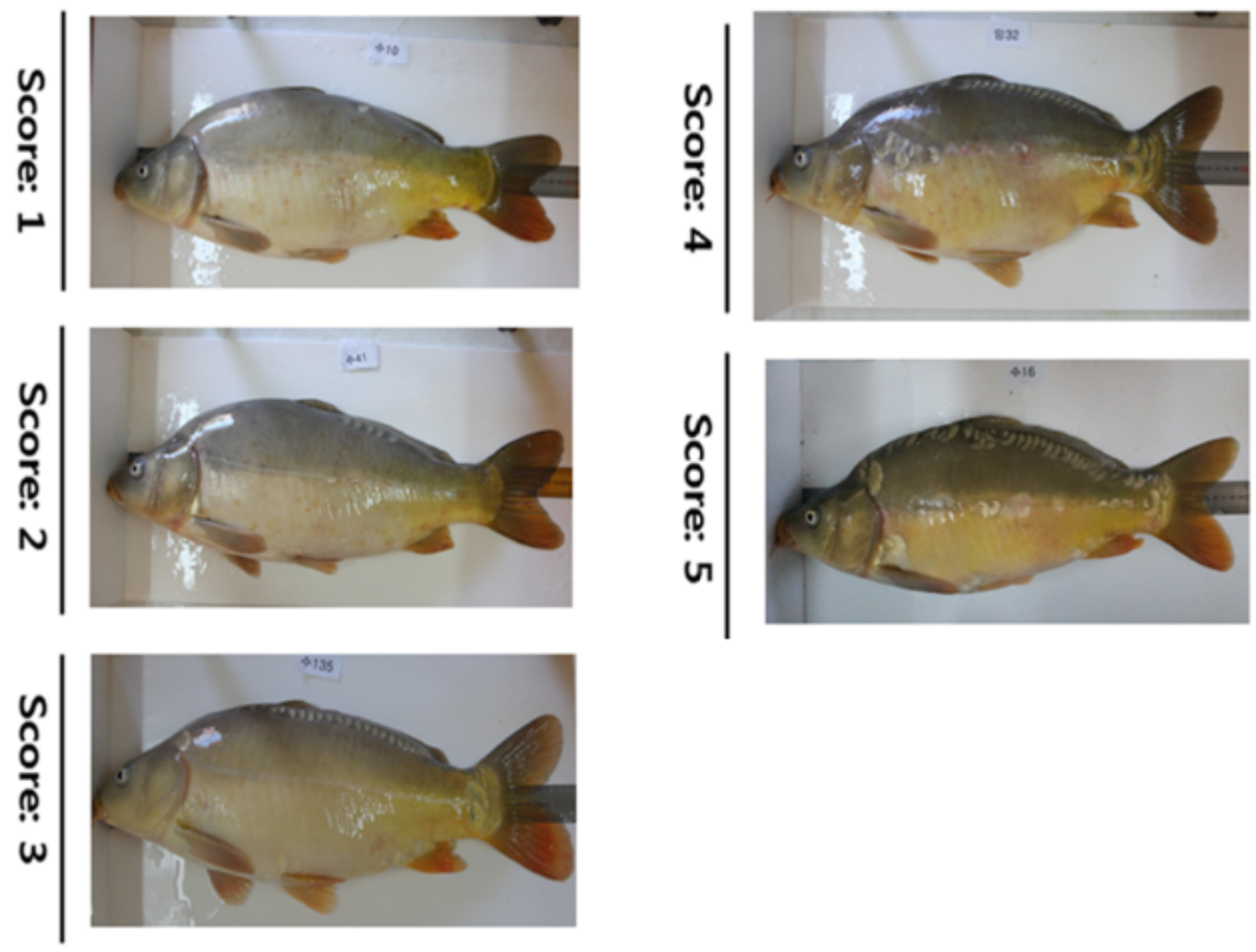

B

Korea
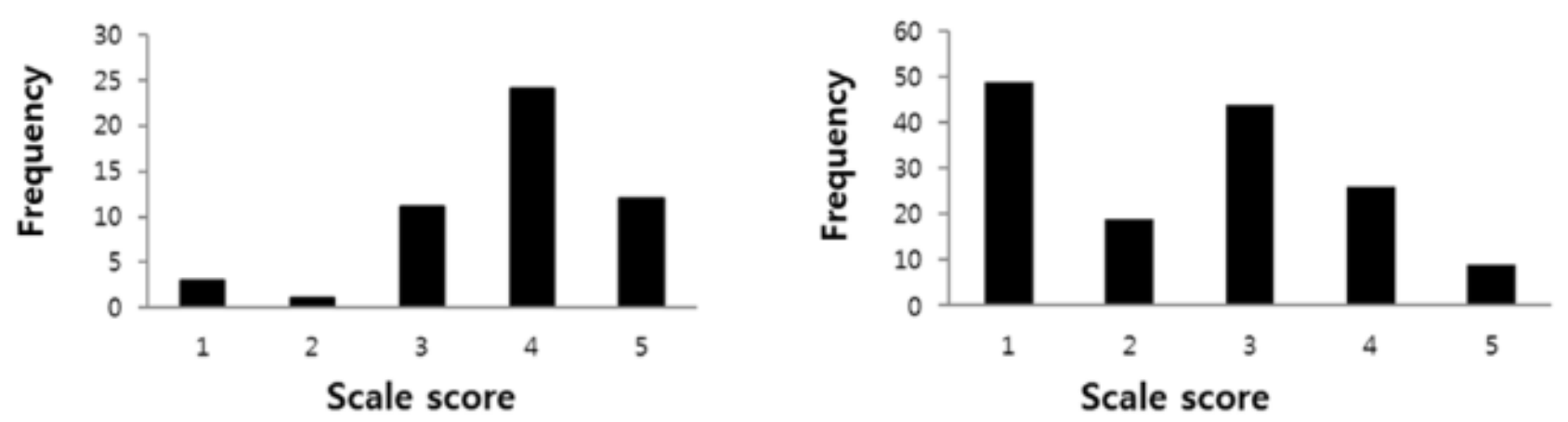

Figure 1

Evaluation standard set of scale expression in Cyprinus carpio broodstock (A). In order to estimate the incidence of scales, the scoring system was set from 1 to 5 according to the degree of a body scale. Scale index measured for each group was based on the score. Distribution of scale scores among the broodstock F0 fish of the Korean Israeli carps and the Chinese Israeli carps (B). 


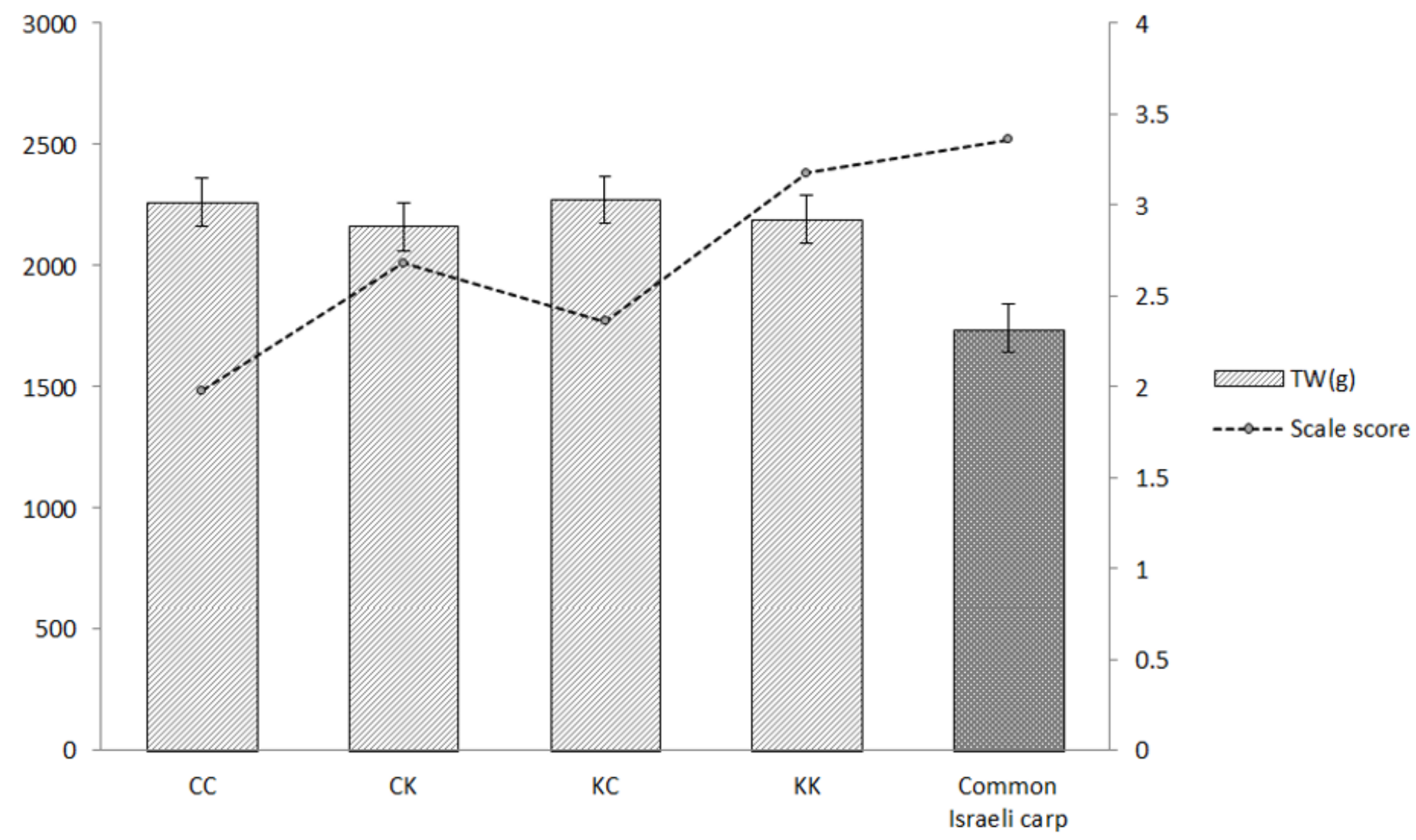

Figure 2

Comparison of scale and weight in the F1 group and common Israeli carp. 


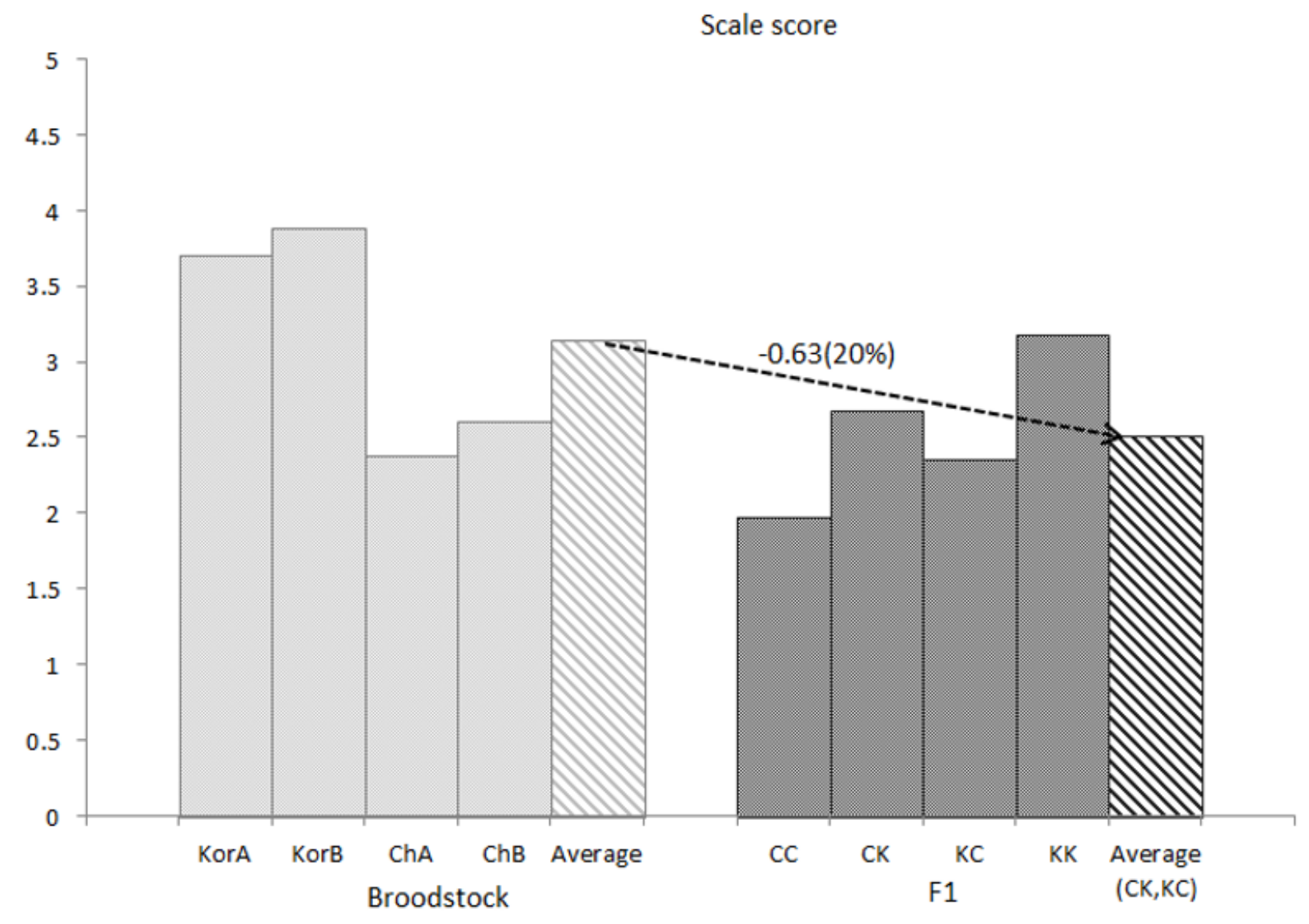

口KorA

$\square$ KorB

$\square \mathrm{ChA}$

$\square \mathrm{ChB}$

$\square$ Average

ए

$\mathrm{DKC}$

$\mathrm{EK}$

$\Delta$ Average

$(\mathrm{CK}, \mathrm{KC})$

Figure 3

Comparison of scale the broodstocks (F0) and F1 group.

\section{Supplementary Files}

This is a list of supplementary files associated with this preprint. Click to download.

- Tables.pdf 